\title{
Antioxidant and anti-diabetic properties of Spirulina platensis produced in Turkey
}

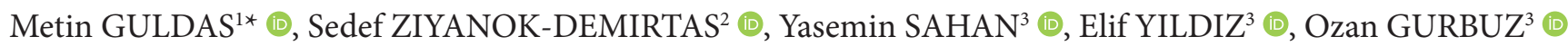

\begin{abstract}
Spirulina produced in Turkey has a high antioxidant capacity determined by the three common methods (ABTS, CUPRAC, and DPPH). The major phenolics found in Spirulina were acacetin (53.62\%) and pinocembrin (41.28\%). The bio-accessibility values of the phenolic compounds in Spirulina were approximately 60\%. PUFA's are the significant antioxidant compounds to prevent lipid peroxidation. Spirulina has been found to reduce blood sugar and oxidative stress due probably to the high amount of $\omega-6$ PUFA. By the treatment of Spirulina, the levels of antioxidant enzymes (GSH-Px and SOD) were increased 240 and 60\% in the healthy rats, while 19 and 59\% in the diabetics. In diabetic rats fed with Spirulina, glucose, triglyceride, total cholesterol levels in blood and malondialdehyde content in body tissues were decreased by $20,31,22$ and up to $56 \%$, respectively. In-vitro and in-vivo tests have shown that Spirulina has anti-hyperglycaemic, anti-hyperlipidaemia and antioxidative effects on diabetic rats.
\end{abstract}

Keywords: Spirulina platensis; antioxidant capacity; anti-diabetic; anti-hyperlipidaemic; oxidative stress.

Practical Application: Antioxidant, anti-diabetic and anti-hyperlipidemic properties of Spirulina produced in Turkey.

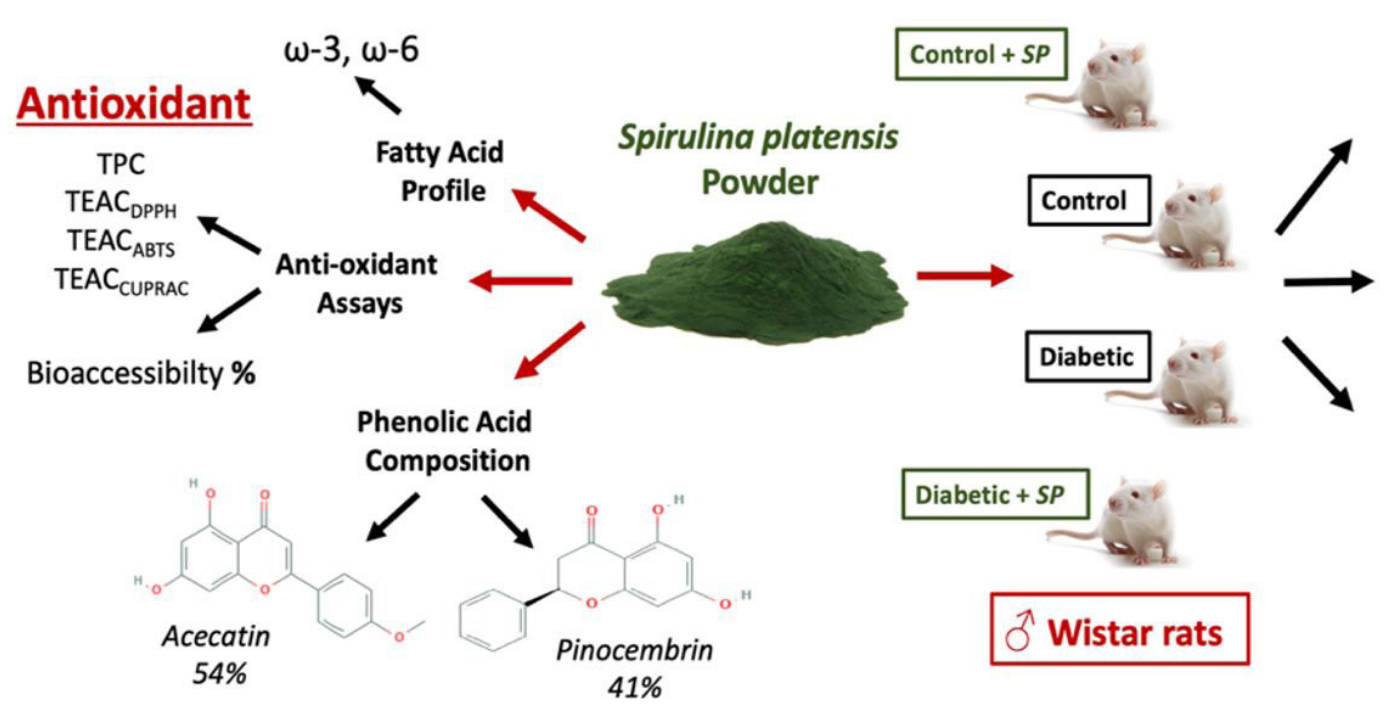

Anti-Diabetic

Glucose

Insulin

Anti-Lipidemic

Triglyceride

Total Cholesterol

Antioxidant

Markers

GSH-Px Enzyme

SOD Enzyme

MDA

Graphical abstract: TOC-Table of content.

\section{Introduction}

Diabetes mellitus is a systemic chronic metabolic disease characterized by clinical and biochemical indications of hyperglycaemia, dyslipidaemia, and glycosuria. There are a number of factors in the aetiology of diabetes mellitus. The prevalence of the disease mostly depends on genetic reasons, physiological factors, sedentary lifestyle, and obesity. Dietary habits such as high consumption of sugar and saturated fats are thought to be the main contributing factors to disease progression. There has been found a strong correlation between the several chronic diseases e.g. diabetes and consumption of polyunsaturated fatty acids (PUFA's) e.g. $\omega-6$ and $\omega-3$ in the diet (Neuman et al., 2017).

One of the main reflections of these chronic diseases in the body is hyperglycaemia that causes non-enzymatic glycation of proteins, glucose oxidation and oxidative degradation of these 
proteins. During the normal oxygen cycle or consumption in the body, free radicals are constantly produced by mitochondria. These free radicals are the initiation factors that can cause changes in the structure of lipids, proteins and nucleic acids. As a result of oxidation of those compounds that was caused by the free radicals, oxidative stress in the body increases and causes disruption of the balance between pro-oxidants and antioxidants in favour of pro-oxidants. Lipid peroxidation that causes oxidation of polyunsaturated fatty acids (PUFA) available in the biological membranes is initiated by reactive oxygen species that are responsible from the oxidative stress. In this cumulative reaction, MDA is formed as the final product of lipid peroxidation (Shinde et al., 2012). Lipid metabolism of diabetics also tends to deteriorate. When lipid profile of a diabetic person deteriorates; sensitivity to the lipid peroxidation and thus the risk of atherosclerosis increases. Therefore, hyperlipidaemia is a significant risk factor for atherosclerotic vascular disorders in diabetes. On the other hand, oxidative stress is closely related to the elevated sugar level in the blood. There has been found a close correlation between diabetes-based complications and the lipid profile in diabetic patients. In previous studies, S. platensis has been recommended as a food supplement that can reduce blood glucose and oxidative stress due to its antioxidant properties (Johansen et al., 2005). However, there is still a need to investigate its antioxidant effects on living organisms e.g. test animals. Antioxidant enzyme levels are among the parameters that have been used to evaluate antioxidant effects of some food components in the body. Biochemically, the activation of the antioxidant enzymes in the body and the balance between oxidants and antioxidants are strongly related to the anti-oxidative compounds consumed in diet. The most known antioxidant enzymes to evaluate oxidation stress in the body are glutathione peroxidase (GSH-Px) and superoxide dismutase (SOD) (Yegin \& Mert, 2013). In recent years, many studies have been conducted to clarify the connection between consumed antioxidants in diet and chronic/metabolic diseases. For example, Spirulina is described as a superfood that can help to control metabolic syndrome (van den Driessche et al., 2018). In another research, Spirulina has been found to act as a free radical scavenger to inhibit lipid peroxidation and prevent DNA damage in fish (Abdelkhalek et al., 2015).

In nature, Spirulina is a microalgae growing in alkaline waters of the tropical regions and its industrial production has been developing very fast in recent years. Spirulina is blue-green algae and non-toxic species of cyanobacteria. Spirulina has been consumed as a food supplement due to its high protein content, essential amino acids, vitamins (vitamin $\mathrm{B}_{12}, \mathrm{~B}_{6}, \mathrm{~B}_{2}, \mathrm{~A}$, and $\mathrm{E}$ ), minerals (Fe, $\mathrm{Ca}, \mathrm{P}, \mathrm{Mg}, \mathrm{Zn}, \mathrm{Cu}, \mathrm{Cr}, \mathrm{Mn}, \mathrm{Na}, \mathrm{K}$, and $\mathrm{Se}$ ), enzymes, essential fatty acids, and other nutrients (Guldas \& Irkin, 2010). It has been defined as a GRAS (Generally Recognized as Safe) food supplement by FDA in 2011. Although there have been conducted many studies related to Spirulina, limited number of studies regarding its effect on chronic and metabolic diseases has been done so far. In one of the newest studies, S. platensis has been found to contribute positively to glucose tolerance in the rats treated with fatty and high sucrose diet (Wan et al., 2019).

Phenolic compounds having antioxidant potential have been intensely investigated in recent years. As one of the phenolic constituents of Spirulina, pinocembrin (5,7-dihydroxyflavone) is a flavonoid that has hepatoprotective, anti-inflammatory, antibacterial effects (Shen et al., 2019). Pinocembrin as an anti-glycation agent has a suppressing effect on the enzymatically-induced glycation in the presence of high level of glucose (Potipiranun et al., 2018). Acacetin is another important phenolic compound available in Spirulina that has anti-peroxidative and anti-plasmodial properties. Acacetin is a phenolic that acts as an $\alpha$-glucosidase inhibitor, radical scavenger, and glucose receptor (Sun et al., 2018).

Spirulina is a natural product that has high antioxidant properties due to its phenolic components and polyunsaturated fatty acids. In our study, in order to evaluate the antioxidant properties of Spirulina; total phenolic content and phenolic profile were investigated at first. It is obvious that bioavailability of food components into the systemic circulation differs due to many complex chemical and/or biochemical reactions seen during digestion. None of the food components is fully absorbed by the human gastrointestinal system and therefore, bioavailability that is a term that means the rate of absorption from the site of administration to the systemic blood circulation, is more important concept than the amount of food or food component consumed. But, determination of bioavailability is too difficult in vitro conditions. Thus, bioaccessibility that means the total amount of a food compound is potentially available for absorption was used to express rate of absorption for the food components in our research.

In recent years, functional and nutritional potentials of Spirulina have been investigated by many researchers. In this research, antioxidant capacity, phenolic contents (Hydrolyzable and extractable ones), bioaccessibility, phenolics and fatty acid profile of Spirulina that has been produced in the climatic conditions of Turkey, were determined. On the other hand, anti-hyperlipidemic, anti-hyperglycaemic and antioxidant effects of Spirulina on the selected blood parameters in the living organisms were examined.

\section{Materials and methods}

\subsection{Materials and reagents}

Spirulina was provided in powdered from Iskoc Corp., Mugla, Turkey. All reagents utilized in analyzing were in analytical-grade purity. High-quality water was used and obtained from a Milli-Q system (Millipore, Bedford, MA, USA). Ethanol and methanol (Merck, CAS Number: 64-17-5, Darmstadt, Germany) were used in the analyses. Carbohydrate (glucose, fructose, and saccharose) standards were supplied from Sigma-Aldrich (St. Louis, USA). The phenolic acids (cafeic, chlorogenic, neochlorogenic and gallic) and flavonoids (kaempferol, quercetin, luteolin, apigenin, pinocembrin, pinoquercetin, 3,3-dimethylquercetin, sakuranetin, taxifolin, methylquercetin and acacetin) were purchased from Sigma-Aldrich (St. Louis, USA) and Fluka Chemie AG (Buchs, Switzerland). The other chemicals used for the analyses are as follows: Trolox (6-hydroxy-2,5,7,8-tetramethylchroman-2-carboxylic acid, CAS Number: 53188-07-1), DPPH (1,1-Diphenyl-2-picryl hydrazine, CAS Number: 1898-66-4), ABTS (2,20-azinobis-(3-ethyl benzothiazoline-6-sulfonic acid, CAS Number: 30931-67-0), gallic acid (CAS Number: 149-91-7) pepsin (CAS Number: 
9001-75-6) and pancreatin (Catalog Number: 1071301000) from Sigma-Aldrich (St. Louis, USA); gallic acid and neocuproin from Merck (CAS Number 484-11-7, Darmstadt, Germany) and bile salt from Thermo Scientific (Catalog number: LP0055J Waltham, Massachusetts, USA); ELISA kits for insulin YLA00337RA YL, GSH-Px YLA0119RA YL and SOD YLA0115RA YL from Biont, Shanghai were purchased.

\subsection{The test animals}

Thirty-six adult male Wistar rats were used. The weights of the rats were approximately 350-400 g. The rats were allowed free access to standard laboratory chow and three rats were housed in per cage. This study was conducted according to the ethical procedures and policies approved by the Committee for Animal Care and Usage of Bursa Uludag University, Bursa, Turkey (Licence number: 2019-02/06). Animals were randomized and divided into four groups as the healthy rats (control group) "C", the healthy rats fed with Spirulina "C+S", the diabetic rats " $D$ ", and the diabetic rats fed with Spirulina " $D+S$ ". Each group was contained nine rats. After the induction period (one week) that is a process to make rats diabetic was completed; the rats were divided into two groups as $\mathrm{C}+\mathrm{S}$ and $\mathrm{D}+\mathrm{S}$ and were fed with powdered Spirulina (50 $\mathrm{mg} / \mathrm{kg}$ ) during four weeks by means of the gavage application which means the administration of Spirulina-water mixture to the rats, through a tube leading down the throat to the stomach. The test animals were fed with the pre-determined dose of Spirulina as recommended by Joventino et al. (2012) and Garcia et al. (2018).

\section{Induction process of the rats}

The intraperitoneal injection of streptozotocin (Sigma-Aldrich, St. Louis, USA) was used to induce diabetes in the Wistar rats. Streptozotocin $(65 \mathrm{mg} / \mathrm{kg})$ that was dissolved in sodium citrate buffer ( $\mathrm{pH} 4.5)$ previously, was used for the injection. The citrate buffer only was injected to the control rats (C). Blood glucose concentration was measured $48 \mathrm{~h}$ after the streptozotocin (STZ) injection. In our study, the rats have the blood glucose concentration is $200 \mathrm{mg} / \mathrm{dL}$, were considered as diabetic and used for the tests.

\subsection{Analyses}

\section{Sampling and measuring of blood parameters}

Blood sampling was made under anaesthesia from the chest area. Blood samples were centrifuged (1500 rpm, Nuve NF 200, Turkey) to separate the serum and plasma for $10 \mathrm{~min}$. Separated samples were stored $-20{ }^{\circ} \mathrm{C}$. The organ tissues including heart, muscle, skeletal muscle and liver were taken just after blood collection, washed with saline solution and stored at $-20{ }^{\circ} \mathrm{C}$ to use for the analyses.

The parameters including insulin, glutathione peroxidases (GSH-Px) and superoxide dismutase (SOD) were determined by ELISA kit. Blood glucose level was measured with the blood sample taken from the rat tail once a week with a glucometer (Optima, Taiwan). For the lipid and the peroxidation assays, blood samples were transferred into EDTA-containing tubes at first, followed by centrifugation, and then the plasma phase was separated and analysed. Triglyceride (TG) and total cholesterol (TC) were measured in the autoanalyzer (TCHO-P 238608 kit for TG; TG-P 223104 kit for TC - Fuji Dri-Chem, Japan). The level of plasma malondialdehyde (MDA) which is an indicator of lipid peroxidation was determined spectrophotometrically (Nanocolor VIS II model, Macherey-Nagel, Germany) by Kamal et al. (1989) and expressed as $n$ mole/mg MDA for each type of tissue. The fluid and the food consumptions on a daily base and the body weight with the blood glucose levels (Optima, Taiwan) on a weekly base were determined.

\subsection{Physico-chemical analyses}

Some physico-chemical properties of Spirulina such as $\mathrm{pH}$, total titratable acidity, ash content, crude fiber and crude lipid were analysed. $\mathrm{pH}$ value was measured by $\mathrm{pH}$-meter (S220-K Seven Compact, Mettler Toledo, Switzerland) and total acidity was determined by $0.1 \mathrm{~N} \mathrm{NaOH}$, expressed as malic acid equivalent. The moisture and ash content were determined according to Rebolloso Fuentes et al. (2000) and given as g/100g sample. Dietary fiber content was evaluated by AOAC method of 985.29 (Association of Official Analytical Chemists, 2007) and crude lipid content was determined according to D'Oca et al. (2011).

\subsection{Total phenolics and antioxidant capacity}

Antioxidant capacity and total phenolics of Spirulina samples were measured by three different extraction procedures (extractable, hydrolysable and bioaccessible) according to Vitali et al. (2009). For the extractable phenolics, $0.5 \mathrm{~g}$ of sample was mixed with $\mathrm{HCl}$ conc/methanol/water (1:80:10, v/v) solution. Then, the mixture was shaken in a water bath (Thermo Fisher Scientific Inc., Waltham, MA, USA) at $20{ }^{\circ} \mathrm{C}$ and $250 \mathrm{rpm}$ for $2 \mathrm{~h}$. The extracts were centrifuged at $3500 \mathrm{rpm}$ in $3 \mathrm{~K} 30$ centrifuge (Sigma, Germany) at $4{ }^{\circ} \mathrm{C}$ for $10 \mathrm{~min}$. The residue of extractable phenolics was mixed with methanol/ $\mathrm{H}_{2} \mathrm{SO}_{4}(10: 1)$ and kept in a shaking water-bath at $250 \mathrm{rpm}$ and $85^{\circ} \mathrm{C}$ for $20 \mathrm{~h}$ to obtain hydrolysable phenolics. Following, the extracts were cooled to the room temperature and then, they were centrifuged at $4{ }^{\circ} \mathrm{C}$ and $3500 \mathrm{rpm}$ for $10 \mathrm{~min}$. In-vitro digestion enzymatic extraction procedure (Bouayed et al., 2012) was used to determine bioaccessible phenolic by means of the model artificial digestion. For the gastric digestion, $0.5 \mathrm{~g}$ of Spirulina sample was treated with the pepsin enzyme $(40 \mathrm{mg} / \mathrm{mL}$ in $0.1 \mathrm{M} \mathrm{HCl})$ at $37^{\circ} \mathrm{C}$ and $250 \mathrm{rpm}$ for $2 \mathrm{~h}$. Then, the intestinal digestion procedure was applied with porcine pancreatin enzyme $(2 \mathrm{mg} / \mathrm{mL})$ and porcine bile mixture $(12 \mathrm{mg} / \mathrm{mL})$ at $37^{\circ} \mathrm{C}$ and $250 \mathrm{rpm}$ for $2 \mathrm{~h}$. The extracts were finally centrifuged at $15^{\circ} \mathrm{C}$ and $3500 \mathrm{rpm}$ for $10 \mathrm{~min}$. The samples obtained by the three different extraction procedures were stored at $-18^{\circ} \mathrm{C}$ for the analyses.

\section{Antioxidant capacity}

The antioxidant capacity of the prepared extracts was determined by three common methods as ABTS (2,20-azinobis-(3-ethyl benzothiazoline-6-sulfonic acid) diammonium salt), DPPH (2,2diphenyl-1-picrylhydrazyl) and CUPRAC (Cupric reducing 
antioxidant capacity). The analytical procedures were slightly modified and performed as proposed by Apak et al. (2008). Absorbances of the extracts were read spectrophotometrically and expressed as $\mu$ mole Trolox equivalent (TE) per g dry weight sample (mean \pm SD for triplicates).

\section{Total phenolic content}

Total phenolic content was evaluated by the Folin-Ciocalteu method (Apak et al., 2008). Absorbances of the extracts were measured by spectrophotometer (UV Mecasys Optizen 3220, Daejeon, Republic of Korea). The results were determined as mg gallic acid equivalents (GAE) per $100 \mathrm{~g}$ dry weighed sample and expressed as the mean \pm standard deviation (SD) for triplicates.

\subsection{HPLC analysis of Spirulina}

\section{Sample preparation}

The Spirulina samples dried were prepared for HPLC analyses according to Yousef et al. (2013). The Spirulina samples dried (2.5-3.0 g) were extracted with $0.3 \%$ acetic acid $(30 \mathrm{~mL})$ and prepared in $\mathrm{MeOH} / \mathrm{H}_{2} \mathrm{O}(70: 30, \mathrm{v} / \mathrm{v})$ using a high-speed homogenizer (IKA Ultra-Turrax) for $2 \mathrm{~min}$. The contents were then transferred into $50 \mathrm{~mL}$ tubes and vortexed for 3-4 s. Then, they were centrifuged at $4000 \mathrm{rpm}$ for $15 \mathrm{~min}$ at $20^{\circ} \mathrm{C}$. The collected supernatants were transferred into volumetric flasks $(100 \mathrm{~mL})$. Acetic acid solution $(20 \mathrm{~mL}$ and $0.3 \%)$ was added on to the precipitated part in the flask and waited for $15 \mathrm{~min}$ at room temperature. During the period, the mixture was vortexed three times for $5 \mathrm{~min}$ of time intervals. The supernatant phases were collected in the flask and the final volume was adjusted to $100 \mathrm{~mL}$ with the extraction solvent pre-identified. The extracted phases were also mixed to obtain completely homogenized sample. The sample $(3 \mathrm{~mL})$ was filtered into the HPLC vials using $0.2 \mu \mathrm{m}$ PTFE syringe filters (Fisher Scientific, New Hampshire, USA). The sample (10 $\mu \mathrm{L})$ taken from each vial, was injected into the HPLC. If the sample was not used immediately, was stored at $-20^{\circ} \mathrm{C}$.

\section{Determination of phenolic profile}

The extraction of phenolics was made according to Wahdan (1998). Phenolic composition of the samples was determined according to the method proposed by Socha et al. (2009). At first, the samples were weighed $(5 \mathrm{~g})$ and dissolved in $0.2 \mathrm{M}$ of $\mathrm{HCl}$ solution. The prepared solution was saturated with $\mathrm{NaCl}$ and the phenolic compounds were extracted with ethyl acetate (Merck, Darmstadt, Germany). The sample solutions $(20 \%, w / v)$ were acidified with $\mathrm{HCl}$ solution until the level of $\mathrm{pH} 2$ was provided. After that, the solutions were saturated with approximately $10 \mathrm{~mL}$ of sodium chloride (Merck; Darmstadt, Germany) solution $(30 \% \mathrm{w} / \mathrm{v})$. The final solutions were extracted with the ethyl acetate solutions at the three stages $(1 \times 50 \mathrm{~mL}$ and $2 \times 25 \mathrm{~mL}$ ). Ethyl acetate was evaporated from the collected extracts at approximately $40^{\circ} \mathrm{C}$ under vacuum. The residue was dissolved in $5 \mathrm{~mL}$ of methanol (Merck; Darmstadt, Germany) and stored at $-18^{\circ} \mathrm{C}$. Then, the extracts were filtered by Millex-LCR syringe filters (PTFE) for the HPLC (High-performance liquid chromatography) equipment (Thermo ScientificTM DionexTM UltiMateTM 3000 RSLC system Waltham, Massachusetts, USA). The recovery rate of phenolic compounds was compared with the pre-defined phenolic standards as follows.

\section{Recovery rate}

To determine the efficacy of the extraction method, $1 \mathrm{mg}$ of the standard phenolic acids was added into the sample. Ten different samples were used for spiking and $10 \mu \mathrm{L}$ of each sample extract was injected into the HPLC instrument. Comparison of the spiked samples was made versus the samples extracted without the addition of commercial standards. The recovery of standard compounds was measured by comparing the difference between the sample and the sample contained the commercial standard. For each compound, the recovery was calculated with the following formula: (TCA-CA)/TCA $\times 100$ ), where $\mathrm{CA}$ is amount of compound in the sample extract $(\mu \mathrm{g})$ without spiking and TCA is the amount of total compound $(\mu \mathrm{g})$ in spiked sample extract.

Phenolic acids such as chlorogenic, caffeic, neochlorogenic and gallic acid were detected at $280 \mathrm{~nm}$ absorbance value, some flavonoids such as apigenin, pinocembrin and acacetin were measured at $290 \mathrm{~nm}$ and while the other flavonoids (luteolin, quercetin, pinoquercetin, 3,3-dimethylquercetin, sakuranetin, taxifolin, methylquercetin and kaempferol) were determined at $330 \mathrm{~nm}$. The mobile phase was eluted at a flow rate of $1 \mathrm{~mL} / \mathrm{min}$ using the solutions of acetic acid (Sigma-Aldrich, St. Louis, USA) and $2.5 \mathrm{~g} / 100 \mathrm{~mL}$ of acetonitrile (Merck, Darmstadt, Germany). The solvent circulation was conducted as following: It was initiated with $3 \%$ of acetonitrile and then, the concentrations were increased to $8,15,20,30$ and $40 \%$ for 10, 20,30, 40 and $50 \mathrm{~min}$, respectively. Finally, the column was eluted isocratically with acetonitrile before the following injection. The compounds were separated with a LiChrosorb column $(\mathrm{C} 18,250 \times 4 \mathrm{~mm})$ (Merck, Darmstadt, Germany) at a temperature of $25^{\circ} \mathrm{C}$. Individual phenolic acids and flavonoids were quantified by comparison of standards (Sigma-Aldrich, St. Louis, USA and Fluka Chemie AG, Buchs, Switzerland).

\section{Determination of fatty acid composition}

Lipid extraction procedure was made to determine the lipid content of Spirulina. Then, the lipid phase obtained from the extraction was used to analyse of fatty acid composition. The lipid extraction and determination of the lipid contents were determined according to AOAC (Association of Official Analytical Chemists, 2005). The fatty acids were converted to fatty acids methyl esters (FAME) by the method proposed by Matos et al. (2016). Fatty acids methyl esters (FAME) were determined by gas chromatography (GC-2014, Shimadzu, Kyoto, Japan). The gas chromatograph equipped with a split injection unit (SPL-2014), flame-ionization detector (FID-2014) and Restek capillary column (RTX) which has $105 \mathrm{~m}$ long and $0.25 \mathrm{~mm}$ internal diameter, was used. The column coated with $0.25 \mu \mathrm{m}$ of $10 \%$ cyanopropyl phenyl and $90 \%$ bis-cyanopropyl siloxane, was used. The temperature for the detector and the injector was at $260^{\circ} \mathrm{C}$. The oven temperature was initially set at $140^{\circ} \mathrm{C}$ and kept constant for $5 \mathrm{~min}$. Then, it was increased to $260^{\circ} \mathrm{C}$ with elevated 
temperature steps $\left(2.5^{\circ} \mathrm{C}\right.$ per min $)$ and kept constant for $30 \mathrm{~min}$ at this temperature. The injection volume and the split ratio were $1 \mu \mathrm{L}$ and 10:1. The carrier gas was nitrogen and its flow rate was $2.2 \mathrm{~mL}$ per min at constant pressure $(130.3 \mathrm{kPa})$. The fatty acids were determined to compare the retention times of the selected standards (Sigma, St. Louis, USA). Relative amounts of the fatty acids were calculated according to their chromatographic peak areas. The data of three independent samples was expressed as the mean value \pm standard deviation.

\subsection{Statistical analysis}

SPSS statistical package (SPSS 16.0, Chicago, IL, USA) was used for the statistical analyses. Data were expressed as mean \pm standard deviation (SD). One-way analysis of variance (ANOVA) and Duncan's multiple range tests were carried out to compare means. Kruskal Wallis test, which is a rank-based non-parametric test, has been used if there is statistically significant difference between two or more groups of an independent variable on ordinal dependent or a continuous variable, was also used for data verification. Differences between the groups were identified by the Mann-Whitney $U$ test in where required, too. The level of significance between means were evaluated according to $p<0.05$.

\section{Results and discussions}

\subsection{Physico-chemical properties}

At first, the basic properties of Spirulina were determined as a raw material will be used in the research.

As seen in Table 1, it was verified that it is a rich source of the fiber and the crude lipid, when compared to the other algal sources (Tokusoglu \& Uunal, 2003).

Table 1. Physico-chemical properties of the Spirulina.

\begin{tabular}{ll}
\hline \multicolumn{2}{c}{ Parameter } \\
\hline $\mathrm{pH}$ & $6.95 \pm 0.14^{1}$ \\
Total titratable acidity $(\mathrm{g} / 100 \mathrm{~g})^{2}$ & $6.12 \pm 0.08$ \\
Moisture content $(\mathrm{g} / 100 \mathrm{~g})$ & $5.33 \pm 0.18$ \\
Ash content $(\mathrm{g} / 100 \mathrm{~g})$ & $7.23 \pm 0.14$ \\
Crude lipid $(\mathrm{g} / 100 \mathrm{~g})$ & $7.39 \pm 0.17$ \\
Crude fiber $(\mathrm{g} / 100 \mathrm{~g})$ & $7.45 \pm 0.22$ \\
\hline
\end{tabular}

${ }^{1}$ Mean values $\pm \mathrm{SD}(\mathrm{n}=3) ;{ }^{2}$ Total titratable acidity expressed as malic acid equivalent.

\subsection{Antioxidant capacity}

Foods are the mixtures of many nutrients and chemicals, which have different single and/or complex chemical functions and antioxidant effects (Alavi \& Golmakani, 2017). That is why, three different methods (CUPRAC, ABTS and DPPH) that have commonly been used to determine antioxidant capacity, were used in our research. The effects of Spirulina diet on the antioxidant capacity values are given in Table 2 and ranged from 1.28 to $4.33,1.44$ to 6.21 and 1.64 to $7.11 \mu$ mole trolox/g, respectively. Differences among the antioxidant capacity methods were probably due to the interactions between the compounds available in Spirulina and the active compounds used in the antioxidant capacity measurement method.

\subsection{Total phenolics}

The contents of the total phenolics (extractable, hydrolysable and bioaccesible phenolics) and antioxidant capacity were given in Table 2. In parallel to high total phenolic content, antioxidant capacities of the hydrolysable phenolics were higher than the extractable phenolics. Among extractable, hydrolysable and bioaccesible phenolics, the highest phenolic content was obtained from the hydrolysable phenolics. This was probably caused by experimental hydrolyzation procedure. It is thought that hydrolyzation causes to release some antioxidant compounds such as phenolics. Thus, microalgal matrix of the Spirulina was probably affected by the hydrolyzation procedure that causes to compose some derivate and ions that were released from the complex compounds (Ranneh et al., 2018).

During the extraction, phenolic compounds are generally affected by the chemical structure of the phenolics, extraction method, the particle size and presence of interfering substances. Therefore, it is difficult to identify a standard/uniform procedure that includes all types of extracts, are obtained from various food matrixes. In addition, as similar to typical digestion, some compounds available in food structure can be extracted easily, while some others such as glycosylated ester forms are needed to hydrolyse at first by the intestinal enzymes.

Food processing operations such as homogenization and heat treatment can lead to increase the bioavailability of these components (Abourashed, 2013). That's why; quantity and structure of the extracts can be changed and affected by the treatments used for sample preparation and extraction.

On the other hand, antioxidant capacity can be influenced by the molecular structure (free phenols, glycosides, and iron-phenol chelates e.g.) of polyphenols. In addition, the bioactive properties

Table 2. Total phenol, antioxidant capacity and bioaccessibility of Spirulina.

\begin{tabular}{lccc}
\hline & Extractable Phenolics & Hydrolysable Phenolics & Bioaccessible Phenolics \\
\hline Total Phenol $(\operatorname{mg}$ GAE/100g dw) & $13.65 \pm 0.03^{\mathrm{b} 1}$ & $18.66 \pm 0.63^{\mathrm{c}}$ & $10.11 \pm 0.18^{\mathrm{a}}$ \\
ABTS $(\mu$ mole trolox/g dw) & $1.28 \pm 0.06^{\mathrm{a}}$ & $4.33 \pm 0.46^{\mathrm{c}}$ & $3.29 \pm 0.36^{\mathrm{b}}$ \\
CUPRAC $(\mu$ mole trolox/g dw) & $1.44 \pm 0.26^{\mathrm{a}}$ & $6.21 \pm 0.02^{\mathrm{c}}$ & $4.53 \pm 0.02^{\mathrm{b}}$ \\
DPPH $(\mu$ mole trolox $/ \mathrm{g} \mathrm{dw})$ & $1.64 \pm 0.25^{\mathrm{a}}$ & $7.11 \pm 1.23^{\mathrm{c}}$ & $3.94 \pm 0.02^{\mathrm{b}}$ \\
\hline
\end{tabular}

${ }^{1}$ Mean values \pm SD $(n=3)$ with different superscripts in the same row are significantly different for extractable, hydrolyzable and bioaccessible phenolics $(\mathrm{p}<0.05)$. 
of food nutrients can be affected by the food matrix. Therefore, the availability of phenolics can be limited by the phenolic acids that can be interreacted with the other molecules or the food matrixes (Kasote et al., 2015). Strong linear correlations were found between the antioxidant capacity and the total phenolic content. The samples which have higher phenolic contents, also have higher antioxidant capacities (Table 2).

\subsection{Phenolic profile}

The phenolic profile of the Spirulina was given in Table 3. When it was compared to the standards, 15 different phenolic compounds were detected. The two most abundant phenolic compounds in the Spirulina are acacetin $(35.37 \mu \mathrm{g} / \mathrm{mg})$ and pinocembrin $(27.23 \mu \mathrm{g} / \mathrm{mg})$. The other phenolics determined are sakuranetin, luteolin, kaempherol, methylquercetin, quercetin and apigenin $0.78,0.68,0.53,0.47,0.26$ and $0.25 \mu \mathrm{g} / \mathrm{mg}$, respectively. The phenolics in the Spirulina have antioxidant properties (Andrade et al., 2018). Among these phenolics, apigenin is a compound that able to trigger autophagy in leukaemia cells.

The phenolic acids (gallic acid, caffeic acid, ferulic acid, $p$-coumaric acid, cinnamic acid, syringic acid, protocatechuic acid and chlorogenic acid) and some flavonoids (catechin and epicatechin) have previously found in microalgae and the cyanobacteria by Jerez-Martel et al. (2017). But, as seen from Table 3, it was found that the phenolic profile of Spirulina can be affected by regional differences such as climatic conditions and quantification of phenolics can change according to production and processing conditions.

\subsection{Fatty acid profile}

The polyunsaturated fatty acid (PUFA) contents are given in Table 4. Spirulina is a natural product that contains a significant amount of polyunsaturated fatty acids such as $\omega-3$ and $\omega-6$.

Table 3. Phenolic profiles of Spirulina using RP-HPLC.

\begin{tabular}{lccc}
\hline \multicolumn{1}{c}{ Phenolics } & RT $(\mathrm{min})$ & $\lambda(\mathrm{nm})$ & Conc. $(\mu \mathrm{g} / 100 \mathrm{~g})$ \\
\hline Neochlorogenic acid & 5 & 285 & $0.02 \pm 0.01^{1}$ \\
Chlorogenic & 6 & 285 & $0.01 \pm 0.01$ \\
Luteolin & 7 & 330 & $0.68 \pm 0.09$ \\
Caffeic acid & 8 & 285 & $0.02 \pm 0.01$ \\
Quercetin & 9 & 330 & $0.26 \pm 0.04$ \\
Apigenin & 10 & 290 & $0.25 \pm 0.06$ \\
Pinocembrin & 12 & 290 & $27.23 \pm 0.23$ \\
Gallic acid & 13 & 285 & $0.03 \pm 0.01$ \\
Pinoquercetin & 17 & 330 & $0.08 \pm 0.03$ \\
3,3-dimethyl quercetin & 23 & 330 & $0.13 \pm 0.03$ \\
Sakuranetin & 24 & 330 & $0.78 \pm 0.09$ \\
Taxifolin & 28 & 330 & $0.11 \pm 0.02$ \\
Methylquercetin & 43 & 330 & $0.47 \pm 0.07$ \\
Kaempherol & 45 & 330 & $0.53 \pm 0.04$ \\
Acacetin & 47 & 290 & $35.37 \pm 0.91$ \\
\hline
\end{tabular}

${ }^{1}$ Mean values $\pm \mathrm{SD}(\mathrm{n}=3)$.
In the previous studies, different fatty acid compositions in Spirulina have been reported by the researchers. From the literature survey, it has been detected that the different results can be related to the solvent used for the extraction (Matos et al., 2016). Just as phenolic profile of Spirulina, its fatty acid profile can also be affected by the climate and processing conditions. It has been seen that Spirulina that was produced in another region, can have a different phenolic profile (Matos et al., 2016). In our research, the fatty acids that were found in higher amount were palmitic acid (C16:0) as saturated fatty acid, palmitoleic acid (C16:1) as monounsaturated fatty acid, alpha-linolenic acid (C18:3) as the $\omega-3$ fatty acid and gamma linolenic acid (C18:3) as the $\omega-6$ fatty acid. Among the polyunsaturated fatty acids ( $\omega-3$ and $\omega-6)$, the highest content was obtained from GLA (1866 mg/100 g). This was followed by the other polyunsaturated fatty acids such as $\omega-3$ and $\omega-6$ which are the important food components for human nutrition and health. These were LA (C18:2) with $144.81 \mathrm{mg} / 100 \mathrm{~g}$

Table 4. Fatty acid profile of the Spirulina.

\begin{tabular}{|c|c|}
\hline Fatty Acid & Conc. $(\mathrm{mg} / 100 \mathrm{~g})$ \\
\hline \multicolumn{2}{|l|}{ Saturated Fatty Acids (SFA) } \\
\hline C12:0 & $87.35 \pm 3.11^{1}$ \\
\hline C14:0 & $94.27 \pm 4.26$ \\
\hline C16:0 & $3380.17 \pm 5.41$ \\
\hline C18:0 & $31.94 \pm 4.23$ \\
\hline Other SFA's ${ }^{2}$ & $323.33 \pm 11.06$ \\
\hline Total & $3916.89 \pm 36.12$ \\
\hline \multicolumn{2}{|c|}{ Monounsaturated Fatty Acids (MFA) } \\
\hline C15:1 & $378.45 \pm 11.32$ \\
\hline C16:1 & $546.14 \pm 9.32$ \\
\hline C18:1 & $69.25 \pm 2.45$ \\
\hline Other MFA's ${ }^{3}$ & $97.66 \pm 6.29$ \\
\hline Total & $1091.50 \pm 13.11$ \\
\hline \multicolumn{2}{|c|}{ Polyunsaturated Fatty Acids (PFA) } \\
\hline \multicolumn{2}{|l|}{$\omega-3$} \\
\hline $\mathrm{C} 16: 4$ & $36.14 \pm 3.24$ \\
\hline $\mathrm{C} 18: 3\left(\mathrm{ALA}^{4}\right)$ & $144.76 \pm 4.76$ \\
\hline $\mathrm{C} 20: 5\left(\mathrm{EPA}^{5}\right)$ & $32.65 \pm 2.71$ \\
\hline $\mathrm{C} 22: 6\left(\mathrm{DHA}^{6}\right)$ & $67.49 \pm 3.33$ \\
\hline Total & $281.04 \pm 5.77$ \\
\hline \multicolumn{2}{|l|}{$\omega-6$} \\
\hline $\mathrm{C} 18: 2\left(\mathrm{LA}^{7}\right)$ & $144.81 \pm 18.76$ \\
\hline $\mathrm{C} 18: 3\left(\mathrm{GLA}^{8}\right)$ & $1866.27 \pm 37.37$ \\
\hline $\mathrm{C} 20: 4\left(\mathrm{AA}^{9}\right)$ & $54.86 \pm 4.91$ \\
\hline $\mathrm{C} 22: 5$ & $46.19 \pm 5.54$ \\
\hline Total & $2112.13 \pm 34.29$ \\
\hline
\end{tabular}

${ }^{1}$ Values are expressed as mean \pm SD $(n=3)$; ${ }^{2}$ Other SFA' s (Tridecanoic acid C13:0, Pentadecanoic acid C15:0, Behenic acid C22:0) were not considered due to minor purities; ${ }^{3}$ Other MUFA' s (Margaroleic acid C17:1, Erucic acid C22:1, Nervonic acid C24:1) were not considered due to minor purities; ${ }^{4} \mathrm{C} 18: 3$ (ALA): $\alpha$-Linolenic Acid; ${ }^{5} \mathrm{C} 20: 5$ (EPA): Eicosapentaenoic acid; ${ }^{6} \mathrm{C} 22: 6$ (DHA): Docosahexaenoic acid; ${ }^{7} \mathrm{C} 18: 2$ (LA): Linoleic acid; ${ }^{8} \mathrm{C} 18: 3$ (GLA): Gamma-linolenic; ${ }^{9} \mathrm{C} 20: 4$ (AA): Arachidonic acid. 
and ALA (C18:3) with $144.76 \mathrm{mg} / 100 \mathrm{~g}$ (Table 4). The total amount of $\omega-6$ fatty acids in Spirulina $(2112 \mathrm{mg} / 100 \mathrm{~g})$ is higher than the $\omega-3$ fatty acids $(281 \mathrm{mg} / 100 \mathrm{~g})$. On the other side, the total content of the monounsaturated fatty acids is about $1 / 3$ of the total saturated fatty acids in the Spirulina.

It was determined to have a considerable amount of GLA (88.35\%) among the investigated PUFA, having a crucial anti-oxidant activity due to its three double bonds. The types of fatty acid composition may vary according to the production method and other external conditions like climate.

\subsection{Antioxidant enzymes}

When PUFA's are metabolized in the body, are converted to the sub-components having antioxidant capacity in the body.
Thus, they play role to activate some antioxidant enzymes such as glutathione peroxidase (GSH-Px) and superoxide dismutase (SOD).

The levels of GSH-Px and SOD in the blood are expressed in Figure 1. When the both group of test animals were fed with Spirulina diet; GSH-Px and SOD were found to increase 240 and $60 \%$ in the healthy rats, while they were increased 19 and 59\% in the diabetic rats. It is obvious that the antioxidant components available in Spirulina, caused to a significant antioxidant effect in the rat bodies $(p \leq 0.05)$. It was probably occurred due to cumulative effect of the phenolics and polyunsaturated fatty acids available in Spirulina.

\subsection{Anti-hyperlipidemic and anti-glisemic effects}

Oxidation is a very important reaction in the body in terms of many chronic diseases, e.g. diabetes. As a result of oxidation,
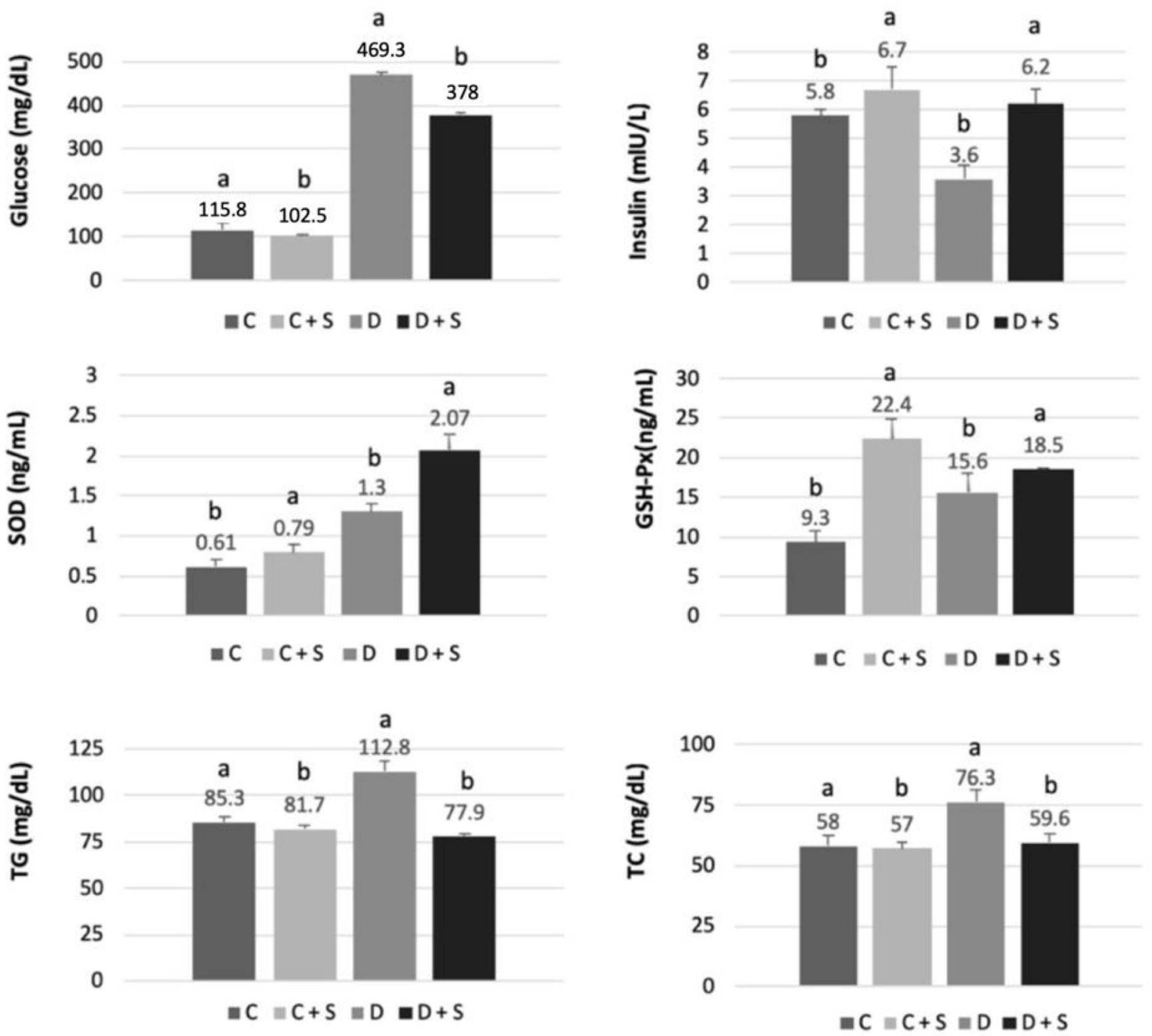

Figure 1. Changes in Glucose, Insulin, SOD, GSH-Px, TG and TC levels in rats. ${ }^{\star} \mathrm{C}$ : Healthy rats as control group; C+S: Healthy rats fed with Spirulina; D: Diabetic rats; D+S: Diabetic rats fed with Spirulina. 
glucose, which is the main energy source of the cells, is oxidized and causes oxidative stress or load in the cell.

In addition to glucose oxidation, hyperglycaemia causes some other reactions, such as oxidative degradation of the proteins and non-enzymatic glycation of proteins that may increase to the formation of free radicals in the body (Singh et al., 2014; Fournet et al., 2018). In our research, levels of triglyceride (TG) and total cholesterol (TC) were observed to increase significantly in the diabetic group versus to the control group, whereas the levels of TG and TC were decreased significantly in the diabetic rats fed with Spirulina (Figure 1). This decrease may be explained by the probable anti-hyperglycaemic effects of Spirulina. The Spirulina mixture has found to reduce body weight and serum lipids in the rats as an ameliorating agent as expressed by Chen et al. (2019).

Antioxidant activity in the body is an important process in terms of glucose oxidation and its damage to body tissues (Paiva et al., 2019). In this regard, interactions related to antioxidant capacity that limits of oxidation damage on the tissues in diabetes are important for health protection. It has been expressed that the glucose tolerance was improved and the hepatic enzyme NADPH oxidase was decreased in the rats treated by the obesogenic diet with S. platensis (Vidé et al., 2018). In our research, glutathione peroxidase enzymes (GSH-Px) were significantly increased in the healthy rats fed by Spirulina ( $\mathrm{C}+\mathrm{S}$ group) compared to the control group (Figure 1). Blood glucose, malondialdehyde (MDA) levels in plasma and tissue were reduced significantly in the diabetic rats fed with Spirulina (D+S group), while serum antioxidant enzyme activity (SOD) were significantly increased in the $D+S$ group versus to the diabetic ones. According to our findings as expected; food consumption, fluid consumption, and blood sugar levels increased significantly in diabetic rats, while their insulin levels and body weight decreased significantly $(p \leq 0.05)$.

On the other hand, oxidative stress causes to excessive increase on free radical concentration in body cells. Free radicals are the compounds formed in the cell as a result of normal metabolic processes, environmental factors and foods consumed. Elevated oxidative stress leads to cell, protein and DNA damage and thus, aging is accelerated. The concentration of malondialdehyde (MDA) is used as a biomarker to evaluate the level of oxidative stress causing DNA damage in an organism. MDA is one of the end products of polyunsaturated fatty acids' peroxidation in the cells. If the free radical concentration increases, excessive production of MDA is also increased. Therefore, plasma and tissue MDA levels are important indicators to evaluate the level of lipid peroxidation. If the concentration of free radicals as the end products of lipid peroxidation increases, the development of many health problems in the body such as atherosclerosis, ischemic and traumatic brain damage are provoked.

The plasma and the tissue MDA levels have also been mentioned to increase in the diabetic rats, previously (Das et al., 2002). In our research, Spirulina consumption was observed to reduce the elevated MDA levels in the tissues of diabetic rats (Table 5). However, tissue MDA levels were also found to show a tendency to decrease in the healthy rats fed with Spirulina ( $\mathrm{C}+\mathrm{S}$ group). Muscle, liver and kidney MDA levels significantly decreased in the $\mathrm{C}+\mathrm{S}$ group as 8,12 and $17 \%(p \leq 0.05)$. Plasma MDA levels tended to decrease in the $\mathrm{C}+\mathrm{S}$ group and significantly decreased in the $\mathrm{D}+\mathrm{S}$ group. This can be explained by hypoglycaemic effect of Spirulina. However, there have also been found controversial studies that antioxidant activity in diabetes can increase or decrease under certain conditions (Yegin \& Mert, 2013; Ferrari, 2017). In this study, antioxidant enzyme (GSH-Px and SOD) activities significantly increased in the diabetic group versus to the control group. The elevated enzyme activity can be explained by the high lipid peroxidation levels in diabetes. In our study, SOD activity was significantly increased in the $\mathrm{D}+\mathrm{S}$ group when compared to the diabetic group. In addition, it was seen that GSH-Px activity tended to increase in the D+S group compared to the diabetes only. It has found that there is strong correlation between the high enzyme activity and other antioxidant properties of Spirulina measured in our research, as seen from Table 2 and Figure 1. Our results are consistent with the other researchers who conducted a research on the antidiabetic effects of Spirulina on the rats (Gargouri et al., 2016).

As previously described, Spirulina is a natural food additive with high antioxidant potential. Compounds that have antioxidant

Table 5. Food and fluid intake, body weight and malondialdehyde (MDA) levels.

\begin{tabular}{lcccc}
\hline \multicolumn{1}{c}{ Parameter } & $\mathrm{C}$ & $\mathrm{C}+\mathrm{S}$ & $\mathrm{D}$ & $\mathrm{D}+\mathrm{S}$ \\
\hline Food intake (g/24h) & $15.5 \pm 0.3^{\mathrm{b}}$ & $24.8 \pm 1.0^{\mathrm{a}}$ & $40.0 \pm 0.8^{\mathrm{a}}$ & $27.0 \pm 0.8^{\mathrm{b}}$ \\
Fluid intake (mL/24h) & $29.3 \pm 1.9^{\mathrm{b}}$ & $35.8 \pm 3.6^{\mathrm{a}}$ & $119.8 \pm 12.2^{\mathrm{b}}$ & $112.5 \pm 8.3^{\mathrm{b}}$ \\
Body weight (g) & $412.3 \pm 5.1^{\mathrm{b}}$ & $434.8 \pm 1.9^{\mathrm{b}}$ & $377.3 \pm 1.3^{\mathrm{b}}$ & $419.5 \pm 1.1^{\mathrm{a}}$ \\
Plasma MDA (nmole/mL) & $2.3 \pm 0.2^{\mathrm{a}}$ & $2.2 \pm 0.8^{\mathrm{b}}$ & $9.1 \pm 0.9^{\mathrm{a}}$ & $4.0 \pm 0.9^{\mathrm{b}}$ \\
Heart MDA (nmole/mg) & $112.7 \pm 1.1^{\mathrm{a}}$ & $97.1 \pm 3.0^{\mathrm{b}}$ & $147.1 \pm 1.6^{\mathrm{a}}$ & $119.0 \pm 6.6^{\mathrm{b}}$ \\
Muscle MDA (nmole/mg) & $109.8 \pm 1.0^{\mathrm{a}}$ & $101.5 \pm 0.7^{\mathrm{b}}$ & $144.4 \pm 2.0^{\mathrm{a}}$ & $125.8 \pm 2.7^{\mathrm{a}}$ \\
Liver MDA (nmole/mg) & $106.7 \pm 4.5^{\mathrm{a}}$ & $93.8 \pm 3.1^{\mathrm{b}}$ & $174.2 \pm 4.0^{\mathrm{a}}$ & $154.2 \pm 5.3^{\mathrm{b}}$ \\
Kidney MDA (nmole/mg) & $118.9 \pm 4.1^{\mathrm{a}}$ & $98.9 \pm 2.0^{\mathrm{b}}$ & $161.8 \pm 3.1^{\mathrm{a}}$ & $125.9 \pm 9.2^{\mathrm{b}}$ \\
\hline
\end{tabular}

${ }^{1}$ Values are expressed as mean \pm SD for rats each group. The number, sex, and breed of test animals (rats) were 36 males and Wistar. The rats were divided into four groups and each group was included 9 rats. Healthy rats as control (C) with the rats fed with Spirulina (C+S) and the diabetic rats (D) with the diabetic rats fed with Spirulina (D+S) were compared in terms of statistical difference according to level of significance $(\mathrm{p}<0.05)$. 
potential in foods are generally bioactive components that contain number of double bonds such as antioxidant vitamins and minerals, flavonoids and phenolic compounds, and $\omega-3$ and $\omega-6$ polyunsaturated fatty acids (Maleki et al., 2019). As determined in our study, it is thought that the antioxidant potential of Spirulina is mainly caused by two components. In our research, Spirulina has found to have high amount of the phenolic compounds such as pinocembrin and acecatin, with $\omega-3$ and $\omega-6$ polyunsaturated fatty acids (Table 3 and 4 ). These substances have the number of double bounds in their molecular structure that are responsible from anti-oxidant effects (Prisacaru, 2016). Pinocembrin is also a phenolic available in propolis, has been found to have antioxidant, hypoglycaemic and anti-hyperlipidemic effects (Granados-Pineda et al., 2018). On the other hand, antioxidant effect of polyphenols is caused by their ability to bind proteins by means of covalent or non-covalent bonds and modifying proteins into insoluble or soluble compounds (Brudzynski \& Maldonado-Alvarez, 2015). High levels of GSH-Px and SOD enzymes detected in Spirulina fed mice (Figure 1), which are commonly considered as the indicators of antioxidant activity in blood, are thought to relate with the high amounts of the phenolic compounds (Table 3 ) and $\omega-3$ with $\omega-6$ fatty acids (Table 4 ).

As monitored in the diabetic mice in our research, the main diagnostic characteristics of diabetes are high levels of blood glucose with excessive feed and fluid consumption and low body weight and insulin level (Table 5). Polyphagia, defined as persistent hunger and eating due to loss of energy in tissues and muscles due to insulin deficiency in diabetes, showed a tendency to recover $33 \%$ in $\mathrm{D}+\mathrm{S}$ group. As a result of insulin deficiency, incomplete energy needs are provided from broken muscle-fat tissues instead of glucose and, this cause to weight loss as seen from the diabetic rats used in our research (Table 5). Type-I diabetes (insulin-dependent diabetes and juvenile diabetes), is a chronic disease in which the pancreas produces insufficient or no insulin hormone. Insulin is a significant hormone that allows glucose to enter cells to generate energy. Spirulina caused to decrease the glucose concentration $11.5 \%$ in control rats and $20 \%$ in diabetic rats. In parallel to changes seen in the glucose concentrations, the insulin levels were increased $15 \%$ in the healthy control rats and $72 \%$ in the diabetic rats due to the consumption of Spirulina.

Undesirable weight loss in the diabetic rat group due to increased insulin secretion was controlled to a certain level in the diabetic rat group fed with Spirulina (D+S) (Table 5). Low glucose level and high insulin level can be associated with the metabolic effects formed in the liver in the diabetic rats fed with Spirulina. Anti-hyperglycaemic properties of Spirulina have also been observed by Gargouri et al. (2016). Spirulina diet as monitored in our research caused to normalize feed and fluid consumption in the diabetic rats.

\section{Conclusion}

Spirulina, which has anti-hyperglycaemic, anti-lipidemic and antioxidant properties, has been found to be effective in protecting against oxidative stress in the rats with Type-I diabetes and can be used as a dietary supplement in the treatment of diabetes. However, these findings should be confirmed by further animal and human tests.
Spirulina, as an increasing food additive in recent years, has a rich phenolic profile, polyunsaturated fatty acids (PUFA) content and high antioxidant capacity. Beside the high antioxidant capacity that was caused by the number of components, e.g. phenolics, Spirulina has significant amount of polyunsaturated fatty acids that have anti-oxidant activity (Choopani et al., 2016). Under the climatic conditions of Turkey, basic quality parameters of Spirulina were investigated. It was determined to have a considerable amount of GLA (88.35\%) among the investigated PUFA, having a crucial anti-oxidant activity due to its three double bonds. As determined in our research, the types of phenolics and fatty acid composition may vary according to the production method and other external conditions like climate.

Spirulina phenolics were found to have high bioaccesibility of approximately $60 \%$ in our study. It can be said that the rate of high bioaccessibility is also confirmed by animal experiments.

It has been mostly observed that MDA levels as an indication of oxidative stress in the diabetic patients tend to increase. In our study, it was observed that MDA levels of test animals decreased with Spirulina diet. In addition to its reducing effect on blood glucose, triglyceride (TG) and total cholesterol (TC); MDA were reduced in heart, muscle, liver, kidney, and plasma as 19, 13, 12, 22 and 56\% in the diabetic rats treated with Spirulina.

Therefore, Spirulina is thought to play an active role to eliminate oxidative damage in diabetes including anti-hyperglycaemic and anti-hyperlipidemic functions.

\section{Acknowledgements}

The authors would like to thank Iskoc Organic Co., Seydikemer, Mugla, Turkey.

\section{References}

Abdelkhalek, N. K., Ghazy, E. W., \& Abdel-Daim, M. M. (2015). Pharmacodynamic interaction of Spirulina platensis and deltamethrin in freshwater fish Nile tilapia, Oreochromis niloticus: impact on lipid peroxidation and oxidative stress. Environmental Science and Pollution Research International, 22(4), 3023-3031. http://dx.doi. org/10.1007/s11356-014-3578-0. PMid:25231739.

Abourashed, E. A. (2013). Bioavailability of plant-derived antioxidants. Antioxidants, 2(4), 309-325. http://dx.doi.org/10.3390/antiox2040309. PMid:26784467.

Alavi, N., \& Golmakani, M. T. (2017). Improving oxidative stability of virgin olive oil by addition of microalga Chlorella vulgaris biomass. Journal of Food Science and Technology, 54(8), 2464-2473. http:// dx.doi.org/10.1007/s13197-017-2689-2. PMid:28740304.

Andrade, L. M., Andrade, C. J., Dias, M., Nascimento, C. A. O., \& Mendes, M. A. (2018). Chlorella and spirulina microalgae as sources of functional foods. nutraceuticals, and food supplements. MOJ Food Processing \& Technology, 6(2), 00144.

Apak, R., Guclu, K., Ozyurek, M., \& Celik, S. E. (2008). Mechanism of antioxidant capacity assays and the CUPRAC (Cupric Ion Reducing Antioxidant Capacity) assay. Mikrochimica Acta, 160(4), 413-419. http://dx.doi.org/10.1007/s00604-007-0777-0.

Association of Official Analytical Chemists - AOAC. (2005). Official Method of Analysis: Oil in Cereal Adjuncts (18th ed., Method 945.16). Gaithersburg: AOAC International. 
Association of Official Analytical Chemists - AOAC. (2007). Official Methods of Analysis. Gaithersburg: AOAC International.

Bouayed, J., Deußer, H., Hoffmann, L., \& Bohn, T. (2012). Bioaccessible and dialysable polyphenols in selected apple varieties following in vitro digestion vs. their native patterns. Food Chemistry, 131(4), 1466-1472. http://dx.doi.org/10.1016/j.foodchem.2011.10.030.

Brudzynski, K., \& Maldonado-Alvarez, L. (2015). Polyphenol-protein complexes and their consequences for the redox activity, structure and function of honey. A current view and new hypothesis-a review. Polish Journal of Food and Nutrition Sciences, 65(2), 71-80. http:// dx.doi.org/10.1515/pjfns-2015-0030.

Chen, H., Zeng, F., Li, S., Liu, Y., Gong, S., Lv, X., Zhang, J., \& Liu, B. (2019). Spirulina active substance mediated gut microbes improve lipid metabolism in high-fat diet fed rats. Journal of Functional Foods, 59, 215-222. http://dx.doi.org/10.1016/j.jff.2019.04.049.

Choopani, A., Poorsoltan, M., Fazilati, M., Latifi, A. M., \& Salavati, H. (2016). Spirulina: a source of gamma-linoleic acid and its applications. Journal of Applied Biotechnology Reports, 3(4), 483-488.

D’Oca, M. G. M., Viêgas, C. V., Lemoes, J. S., Miyasaki, E. K., MorónVillarreyes, J. A., Primel, E. G., \& Abreu, P. C. (2011). Production of FAMEs from several microalgal lipidic extracts and direct transesterification of the Chlorella pyrenoidosa. Biomass and Bioenergy, 35(4), 1533-1538. http://dx.doi.org/10.1016/j.biombioe.2010.12.047.

Das, S., Yadav, D., Narang, R., \& Das, N. (2002). Interrelationship between lipid peroxidation, ascorbic acid and superoxide dismutase in coronary artery disease. Current Science, 83(4), 488-491.

Ferrari, C. K. (2017). Antioxidant defenses in diabetes mellitus: a clinical and molecular approach. Pharmaceuticals, 14, 16.

Fournet, M., Bonté, F., \& Desmoulière, A. (2018). Glycation damage: a possible hub for major pathophysiological disorders and aging. Aging and Disease, 9(5), 880-900. http://dx.doi.org/10.14336/ AD.2017.1121. PMid:30271665.

Garcia, F. A. D. O., Yuen, V. G., Campos, H. S. D., Turatti, E., Viana, G. S. D. B., Oliveira, C. J. F., \& McNeill, J. H. (2018). Spirulina platensis alleviates the liver, brain and heart oxidative stress in Type 1 diabetic rats. Food and Nutrition Sciences, 9(06), 735-750. http://dx.doi. org/10.4236/fns.2018.96056.

Gargouri, M., Magné, C., \& El Feki, A. (2016). Hyperglycemia, oxidative stress, liver damage and dysfunction in alloxan-induced diabetic rat are prevented by Spirulina supplementation. Nutrition Research (New York, N.Y.), 36(11), 1255-1268. http://dx.doi.org/10.1016/j. nutres.2016.09.011. PMid:27865613.

Granados-Pineda, J., Uribe-Uribe, N., García-López, P., Ramos-Godinez, M. D. P., Rivero-Cruz, J. F., \& Pérez-Rojas, J. M. (2018). Effect of pinocembrin isolated from Mexican brown propolis on diabetic nephropathy. Molecules (Basel, Switzerland), 23(4), 852. http://dx.doi. org/10.3390/molecules23040852. PMid:29642511.

Guldas, M., \& Irkin, R. (2010). Influence of Spirulina platensis powder on the microflora of yoghurt and acidophilus milk. Mljekarstvo, 60(4), 237-243.

Jerez-Martel, I., García-Poza, S., Rodríguez-Martel, G., Rico, M., Afonso-Olivares, C., \& Gómez-Pinchetti, J. L. (2017). Phenolic profile and antioxidant activity of crude extracts from microalgae and cyanobacteria strains. Journal of Food Quality, 2017, 2017. http://dx.doi.org/10.1155/2017/2924508.

Johansen, J. S., Harris, A. K., Rychly, D. J., \& Ergul, A. (2005). Oxidative stress and the use of antioxidants in diabetes: linking basic science to clinical practice. Cardiovascular Diabetology, 4(1), 5. http://dx.doi. org/10.1186/1475-2840-4-5. PMid:15862133.
Joventino, I. P., Alves, H. G., Neves, L. C., Pinheiro-Joventino, F., Leal, L. K. A., Neves, S. A., Ferreira, F. V., Brito, G. A., \& Viana, G. B. (2012). The microalga Spirulina platensis presents anti-inflammatory action as well as hypoglycemic and hypolipidemic properties in diabetic rats. Journal of Complementary \& Integrative Medicine, 9(1), 17. http://dx.doi.org/10.1515/1553-3840.1534. PMid:22944720.

Kamal, A.-A. M., Gomaa, A., Khafif, M. E., \& Hammad, A. S. (1989). Plasma lipid peroxides among workers exposed to silica or asbestos dusts. Environmental Research, 49(2), 173-180. http://dx.doi. org/10.1016/S0013-9351(89)80062-3. PMid:2546756.

Kasote, D. M., Katyare, S. S., Hegde, M. V., \& Bae, H. (2015). Significance of antioxidant potential of plants and its relevance to therapeutic applications. International Journal of Biological Sciences, 11(8), 982991. http://dx.doi.org/10.7150/ijbs.12096. PMid:26157352.

Maleki, S. J., Crespo, J. F., \& Cabanillas, B. (2019). Anti-inflammatory effects of flavonoids. Food Chemistry, 299, 125124. http://dx.doi. org/10.1016/j.foodchem.2019.125124. PMid:31288163.

Matos, Â. P., Feller, R., Moecke, E. H. S., de Oliveira, J. V., Junior, A. F., Derner, R. B., \& Sant'Anna, E. S. (2016). Chemical characterization of six microalgae with potential utility for food application. Journal of the American Oil Chemists' Society, 93(7), 963-972. http://dx.doi. org/10.1007/s11746-016-2849-y.

Neuman, J. C., Fenske, R. J., \& Kimple, M. E. (2017). Dietary polyunsaturated fatty acids and their metabolites: Implications for diabetes pathophysiology, prevention, and treatment. Nutrition and Healthy Aging, 4(2), 127-140. http://dx.doi.org/10.3233/NHA-160004. PMid:28447067.

Paiva, A., Gonçalves, D., Ferreira, P., Baldwin, E., \& Cesar, T. (2019). Postprandial effect of fresh and processed orange juice on the glucose metabolism, antioxidant activity and prospective food intake. Journal of Functional Foods, 52, 302-309. http://dx.doi. org/10.1016/j.jff.2018.11.013.

Potipiranun, T., Adisakwattana, S., Worawalai, W., Ramadhan, R., \& Phuwapraisirisan, P. (2018). Identification of pinocembrin as an anti-glycation agent and $\alpha$-glucosidase inhibitor from fingerroot (Boesenbergia rotunda): The tentative structure-activity relationship towards MG-trapping activity. Molecules (Basel, Switzerland), 23(12), 3365. http://dx.doi.org/10.3390/molecules23123365. PMid:30572593.

Prisacaru, A. E. (2016). Effect of antioxidants on polyunsaturated fatty acids-review. Acta Scientiarum Polonorum. Technologia Alimentaria, 15(2), 121-129. http://dx.doi.org/10.17306/J.AFS.2016.2.12. PMid:28071002.

Ranneh, Y., Ali, F., Zarei, M., Akim, A. M., Hamid, H. A., \& Khazaai, H. (2018). Malaysian stingless bee and Tualang honeys: a comparative characterization of total antioxidant capacity and phenolic profile using liquid chromatography-mass spectrometry. Lebensmittel-Wissenschaft + Technologie, 89, 1-9. http://dx.doi.org/10.1016/j.lwt.2017.10.020.

Rebolloso Fuentes, M., Fernández, G. A., Pérez, J. S., \& Guerrero, J. G. (2000). Biomass nutrient profiles of the microalga Porphyridium cruentum. Food Chemistry, 70(3), 345-353. http://dx.doi.org/10.1016/ S0308-8146(00)00101-1.

Shen, X., Liu, Y., Luo, X., \& Yang, Z. (2019). Advances in Biosynthesis, Pharmacology, and Pharmacokinetics of Pinocembrin, a Promising Natural Small-Molecule Drug. Molecules (Basel, Switzerland), 24(12), 2323. http://dx.doi.org/10.3390/molecules24122323. PMid:31238565.

Shinde, A., Ganu, J., \& Naik, P. (2012). Effect of free radicals \& antioxidants on oxidative stress: a review. Journal of Dental and Allied Sciences, 1(2), 63. http://dx.doi.org/10.4103/2277-4696.159144.

Singh, V. P., Bali, A., Singh, N., \& Jaggi, A. S. (2014). Advanced glycation end products and diabetic complications. The Korean Journal of Physiology \& Pharmacology: Official Journal of the Korean Physiological Society and the Korean Society of Pharmacology, 18(1), 1-14. http:// dx.doi.org/10.4196/kjpp.2014.18.1.1. PMid:24634591. 
Socha, R., Juszczak, L., Pietrzyk, S., \& Fortuna, T. (2009). Antioxidant activity and phenolic composition of herbhoneys. Food Chemistry, 113(2), 568-574. http://dx.doi.org/10.1016/j.foodchem.2008.08.029.

Sun, L. C., Zhang, H. B., Gu, C. D., Guo, S. D., Li, G., Lian, R., Yao, Y., \& Zhang, G. Q. (2018). Protective effect of acacetin on sepsis-induced acute lung injury via its anti-inflammatory and antioxidative activity. Archives of Pharmacal Research, 41(12), 1199-1210. http://dx.doi. org/10.1007/s12272-017-0991-1. PMid:29243040.

Tokusoglu, O., \& Uunal, M. K. (2003). Biomass nutrient profiles of three microalgae: spirulina platensis, Chlorella vulgaris, and Isochrisis galbana. Journal of Food Science, 68(4), 1144-1148. http://dx.doi. org/10.1111/j.1365-2621.2003.tb09615.x.

van den Driessche, J. J., Plat, J., \& Mensink, R. P. (2018). Effects of superfoods on risk factors of metabolic syndrome: a systematic review of human intervention trials. Food \& Function, 9(4), 19441966. http://dx.doi.org/10.1039/C7FO01792H. PMid:29557436.

Vidé, J., Bonafos, B., Fouret, G., Benlebna, M., Poupon, J., Jover, B., Casas, F., Jouy, N., Feillet-Coudray, C., Gaillet, S., \& Coudray, C. (2018). Spirulina platensis and silicon-enriched spirulina equally improve glucose tolerance and decrease the enzymatic activity of hepatic NADPH oxidase in obesogenic diet-fed rats. Food \& Function, 9(12), 6165-6178. http://dx.doi.org/10.1039/C8FO02037J. PMid:30431036.
Vitali, D., Dragojević, I. V., \& Šebečić, B. (2009). Effects of incorporation of integral raw materials and dietary fibre on the selected nutritional and functional properties of biscuits. Food Chemistry, 114(4), 14621469. http://dx.doi.org/10.1016/j.foodchem.2008.11.032.

Wahdan, H. A. L. (1998). Causes of the antimicrobial activity of honey. Infection, 26(1), 26-31. http://dx.doi.org/10.1007/BF02768748. PMid:9505176.

Wan, X. Z., Li, T. T., Zhong, R. T., Chen, H. B., Xia, X., Gao, L. Y., Gao, X. X., Liu, B., Zhang, H. Y., \& Zhao, C. (2019). Anti-diabetic activity of PUFAs-rich extracts of Chlorella pyrenoidosa and Spirulina platensis in rats. Food and Chemical Toxicology, 128, 233-239. http://dx.doi. org/10.1016/j.fct.2019.04.017. PMid:30995513.

Yegin, S. C., \& Mert, N. (2013). Investigation on the Hba1c, MDA, GSHPx and SOD levels in experimentally diabetic rats. Van Veterinary Journal, 24(2), 51-54.

Yousef, G. G., Brown, A. F., Funakoshi, Y., Mbeunkui, F., Grace, M. H., Ballington, J. R., Loraine, A., \& Lila, M. A. (2013). Efficient quantification of the health-relevant anthocyanin and phenolic acid profiles in commercial cultivars and breeding selections of blueberries (Vaccinium spp.). Journal of Agricultural and Food Chemistry, 61(20), 4806-4815. http://dx.doi.org/10.1021/jf400823s. PMid:23635035. 